\title{
Polylactide Composites with Finely Divided Fillers
}

\author{
Khrystyna Kysil $^{1}$, Andrii Masyuk ${ }^{1}$, Volodymyr Skorokhoda ${ }^{1}$, Levko Bilyi ${ }^{2}$ \\ 1. Department of Chemical Technology of Plastics, Lviv Polytechnic National University, UKRAINE, Lviv, S. \\ Bandera Street 12, E-mail: masyukas@gmail.com \\ 2. Karpenko Physicomechanical Institute, Ukrainian National Academy of Sciences, UKRAINE, Lviv, Naukova \\ Street 5 .
}

Abstract-Polymer composite materials based on polylactide and fillers of various nature (hydroxyapatite and modified metal-containing silicates) have been obtained. It has been found the properties of the developed materials: melt flow index, Vicat softening point and the surface hardness vary depending on the content and nature of the filler.

Keywords - polylactide, hydroxyapatite, silicate, filler, composite.

\section{Introduction}

The development of industry needs the use of new polymer materials with a set of required characteristics. The increased attention is paid to the environmental safety of such materials, in particular regarding the use of renewable sources of raw materials for their obtaining and the ability to biodegradate. In this regard, the promising material is polylactide (PLA).

\section{Experimental}

PLA is a biodegradable thermoplastic aliphatic polyester with lactic acid monomer. Fillers hydroxyapatite (HA) and modified metal-containing silicates fillers (Ni-SF) [1] were used for the preparation of PLA composites. To obtain composites, mixing of loose components in a drum type mixer and homogenization of the mixture in a Cellier extruder was carried out.

\section{Results and discussion}

The introduction of HA in the PLA leads to a decrease in material fluidity, in particular the value of the melt flow index (MFI $210{ }^{\circ} \mathrm{C}, 2.16 \mathrm{~kg}$ ). Adding $1 \%$ by weight. HA reduces the value of the MFI to $21 \mathrm{~g} / 10 \mathrm{~min}$, MFI of unfilled PLA - $27.2 \mathrm{~g} / 10 \mathrm{~min}$. Further increase in the content of HA to 2, 5, 10 and $20 \%$ by wt. naturally reduces the value of MFI of composite to 16.5, 11.8, 8.2 and $6.7 \mathrm{~g} / 10 \mathrm{~min}$, respectively. It should be noted that HA behaves like a classic inert filler, which is also confirmed by its influence on Vicat softening point of received materials. In particular, unfilled PLA is characterized of Vicat softening point $68.6{ }^{\circ} \mathrm{C}$ and the adding of HA slightly reduces it, with a minimum $65.4{ }^{\circ} \mathrm{C}$ at filling $5 \%$ by wt. Adding of HA increases the value of surface hardness of PLA, which is obviously due to the reduction of free space between the macromolecules of PLA and as a consequence of the decrease of high-elastice deformation of the surface layers of PLA. Other influences have modified Ni-SF, MFI of PLA with $10 \%$ by wt. Ni-SF is $19.3 \mathrm{~g} / 10 \mathrm{~min}$ and for modified Ni-SF by polyvinyl alcohol and polyvinylpyrrolidone 13.2 and $25.2 \mathrm{~g} / 10 \mathrm{~min}$, respectively. This is due to the interaction between the PLA macromolecules and the functional groups of silicate fillers and modifiers.

\section{Conclusion}

Based on the performed studies polylactide composites can be further processed into product by injection molding, extrusion and 3D printing.

\section{References}

[1] V. Levytskyi, A. Masyuk, D. Samoiliuk, L. Bilyi, T. Humenetskyi "Morphology and properties of polymer-silicate composites," Materials Science, vol. 52, no. 1. pp. 17-24., 2016. 